Original Research

\title{
Feasibility of a Perinatal Mindfulness-Based Intervention Delivered Remotely Due to COVID-19
}

Charlotte V. Farewell ${ }^{1}{ }^{*}$, Jessica Walls ${ }^{1}$, Jamie N. Powers ${ }^{1}$, Joanne Whalen ${ }^{2}$, Meredith Shefferman 2 , Jenn A. Leiferman ${ }^{1}$

1. Department of Community and Behavioral Health, University of Colorado-Anschutz Medical Campus, 80045 Aurora, Colorado; E-Mails: Charlotte.farewell@cuanschutz.edu; Jessica.walls@cuanschutz.edu; jamie.powers@cuanschutz.edu; jenn.leiferman@cuanschutz.edu

2. Integrative Medicine Center, UC Health, 80238 Denver, Colorado; E-Mails: joanne.whalen@uchealth.org; Meredith.Shefferman@uchealth.org

* Correspondence: Charlotte V. Farewell; E-Mail: Charlotte.farewell@cuanschutz.edu

Academic Editor: Gerhard Litscher

Special Issue: Yoga and Mindfulness

OBM Integrative and Complementary Medicine 2021, volume 6 , issue 3 doi:10.21926/obm.icm.2103028
Received: June 30, 2021

Accepted: September 01, 2021

Published: September 09, 2021

\begin{abstract}
Mind-body interventions have shown promise for improving prenatal mental health. The purpose of this study was to investigate the feasibility of a prenatal mind-body intervention delivered remotely due to COVID-19 and preliminary efficacy with respect to mental health outcomes. This study used a simultaneous mixed methods approach $(n=27)$. Mixed methods data were collected to evaluate the feasibility and preliminary efficacy of the remotely delivered program (I.e., acceptability, practicality, demand, sustainability). Findings suggests that remote delivery of the Mindful Moms-to-Be program is acceptable. Half of the sample (45\%) reported that they felt remote participation was more acceptable compared to inperson programming and approximately $1 / 3$ reported that either format would be acceptable. Additionally, $36 \%$ of participants reported that remote participation did not impact their ability to participate and $46 \%$ reported that it increased their ability to participate. A majority
\end{abstract}


(63\%) of participants reported feeling moderately or extremely likely to sustain the habits learned in the program after birth. Finally, after participating in the program, participants reported statistically significant increases in resilience $(t(26)=-3.89, p<.01$ ) and statistically significant decreases in stress ( $t(26)=3.45, p<.01)$, depression ( $t(26)=4.04$ ), and anxiety ( $t$ $(26)=4.23, p<.01)$. Remotely delivered mind-body interventions may be feasible for pregnant individuals, increase demand, and potentially lead to sustainable changes in the postpartum period. Participation in Mindful Moms-to-Be may significantly mitigate negative mental health outcomes, including anxiety, during pregnancy.

\section{Keywords}

Perinatal mental health; anxiety; mindfulness-based interventions

\section{Introduction}

Stress impacts human biology, particularly during early periods of development [1, 2]. Pregnancy can be an inherently challenging period that results in changes in mood, lack of sleep, relationship challenges, and isolation for many women [2]. Prenatal stress also influences offspring development through the embedding of environmental exposures [3, 4]. Past research suggests that poor prenatal mental health is positively associated with a constellation of poor physical health and obstetric outcomes, such as cardiovascular disease and preeclampsia [5-8], and negative impacts on birth and child developmental outcomes that may translate to obesity, diabetes and heart disease in adulthood [9-12]. The most recent literature suggests that $16 \%$ of pregnant women are clinically depressed [13], $21 \%$ of pregnant women have anxiety disorders [14], and $12-44 \%$ of pregnant women report high perceived stress $[15,16]$.

Exposure to environmental stressors, such as the COVID-19 pandemic in 2020-2021, can amplify perinatal mood disorders and child health and development outcomes [17-20]. Recent findings suggest that the impacts of disasters on mental health, and specifically anxiety, are particularly pronounced in pregnant and postpartum women [19]. For example, a mixed-methods study of women who were either pregnant or postpartum during the early months of the pandemic revealed that $44 \%$ reported symptoms of anxiety [21]. Alternative recent reports suggest that $30-45 \%$ of perinatal women reporting having anxiety symptoms during 2020 [22, 23]. Untreated perinatal anxiety can result in adverse outcomes for both mother and baby, including preterm birth [24], lack of bond with baby [25], developmental and cognitive delays [26], behavioral problems later in childhood [27], and long term depressive symptoms [28].

As a result of COVID-19, pregnant women were designated as being a high-risk population [29]. Local and national public health guidelines prohibited large group gatherings [30] and called for medical services to transition to tele-health models, including prenatal visits, therapy, and wellbeing programs [31]. Increases in anxiety coupled with these disruptions highlight the negative impacts of social isolation on perinatal mental health, as social isolation has been directly correlated with maternal mental illness [32-34]. Studies examining the effects of social distancing during the COVID19 pandemic show isolation and loneliness in the prenatal period to be predictors of perinatal anxiety and depression [35, 36]. 
Mind-body interventions may improve mental health in pregnant women [37]. MindfulnessBased Stress Reduction (MBSR) was developed by Jon Kabat-Zinn and colleagues [38] and is an example of a mind-body intervention that improves both mental and physical health outcomes through a focus on mindfulness. Mindfulness is a set of skills derived from contemplative traditions and involves the cultivation of moment-to-moment and nonjudgmental awareness of one's present moment experience [39]. Specifically, the use of Mindfulness-Based Cognitive Therapy (MBCT) has been found to be an efficacious psychosocial intervention for maternal mental health through the targeting of mediating factors such as mindfulness [40-42]. MBIs that utilize MBCT during pregnancy may promote positive mental wellbeing via reductions in stress, depression, and anxiety [43-46]. A meta-analysis of 17 studies examining MBls during the perinatal period found significant improvements in depressive symptoms [47]. Although current studies are exploring the specific impacts of COVID-19 on perinatal mental health [48, 49], few studies have examined the application of prenatal MBIs to mitigate perinatal mood disorders during COVID-19 [47, 50]. Additionally, there is a gap in investigating the feasibility of remotely delivered $\mathrm{MBI}$ interventions specifically related to multiple mental health and wellbeing outcomes, including perinatal anxiety during COVID-19. Resilience in the face of disasters is likely to result from a combination of resources that foster the ability to cope well despite extraordinarily severe demands [51]. MBIs delivered remotely have the potential to cultivate positive coping behaviors and social connectedness, which may translate to enhanced prenatal and postpartum mental health and wellbeing, specifically during COVID-19.

\section{Methods}

\subsection{Mindful Moms-to-Be Program}

The Mindful Moms-to-Be program is an example of a prenatal $\mathrm{MBI}$ that is rooted in mindfulnessbased cognitive therapy (MBCT) and mindfulness-based childbirth and parenting (MBCP) [52]. The program is based off a prenatal MBCT program focused on the prevention of perinatal depression $[53,54]$ and consists of six 90 -minute weekly sessions. The goal of the Mindful Moms-to-Be program is to focus on emotional wellness during pregnancy in order to decrease the risk for postpartum depression and anxiety for women who may be at higher risk due to high-risk pregnancies, histories of depression and/or anxiety, and current psychosocial stressors during pregnancies. The program is facilitated by two licensed psychologists and covers various topics such as: mindfulness, breathwork, pregnancy-specific worries and stressors, managing anxiety, working with/accepting difficulty, yoga, pain management, and self-care strategies and exercises. In 2020, due to COVID-19, the Mindful Moms-to-Be program was adapted for remote delivery.

\subsection{Participants}

The final analytical sample for this study included individuals who participated in the remotely delivered Mindful Moms-to-Be program from September of 2020 through April of 2021 ( $n=27$ ). Participants were recruited through paid advertisement on social media platforms (e.g., Facebook, Instagram), and fliers distributed through university-affiliated listservs and email databases, obstetric offices, WIC clinics and pregnancy-based health care clinics. Eligibility criteria included: 1) individuals who were between 12 and 32 weeks pregnant, and 2) individuals living in Colorado. A large university-affiliated institutional review board approved this study (IRB \# 20-2138). 
Additionally, safety monitoring with respect to depression and anxiety was conducted by two licensed psychologists throughout the course of the study.

\subsection{Procedure}

Individuals who were interested in participating in the program were screened for eligibility by the licensed psychologists who facilitated the program. Once individuals were deemed eligible and interested, an electronic link containing the consent and baseline survey was sent via email. All documents (consent, survey) were administered via REDCap [55].

REDCap is a secure, web-based application designed to support data capture for research studies. Once individuals completed the baseline survey, the licensed psychologists emailed information regarding the program and logistics on how to join the group sessions. Survey data was collected at two timepoints: T1 (baseline) and T2 (post-intervention). Additionally, mixed methods data were collected after participation in the program (T2) to evaluate the feasibility of the remotely delivered program. Individuals were recruited for participation in the feasibility data collection using a convenience sampling design; the post-survey included a question about interest in participating in the feasibility components of this study (brief survey and 45-min zoom interview). The study team contacted individuals who expressed interest in participating and conducted the additional data collection activities. Individuals received a \$20 electronic Target gift card for all surveys and interviews that they completed.

\subsection{Instruments}

\subsubsection{Feasibility Data}

The 13-item feasibility survey and 16-item semi-structured interview guide were comprised of questions about acceptability (e.g., satisfaction), practicality (e.g., ability to participate), demand (e.g., session attendance and engagement), and sustainability (e.g., perceived likelihood of sustaining behaviors into postpartum period). Feasibility constructs and associated questions were based on best practices related to feasibility studies and implementation research and are displayed in Table 1 [56]. Sample survey questions included, "Overall, how satisfied are you with the Mindful Moms-to-Be program?" (acceptability) and "How did remote delivery impact your ability to participate?" (practicality). Sample interview questions included, "How likely do you think you are to sustain the habits you learned in the program after birth?" (sustainability) and "When signing up for the program, what encouraged you to sign up? What hesitations did you have?" (demand).

Table 1 Feasibility constructs, evaluation questions, methods and timepoints of data collection.

\begin{tabular}{llll}
\hline Construct & Evaluation Questions & $\begin{array}{l}\text { Data } \\
\text { collection } \\
\text { methods }\end{array}$ \\
\hline Acceptability & $\begin{array}{l}\text { To what extent is the Mindful Moms to Be program } \\
\text { considered suitable? }\end{array}$ & $\begin{array}{l}\text { Survey, T2 } \\
\text { Interview }\end{array}$
\end{tabular}




$\begin{array}{llll}\text { Practicality } & \begin{array}{l}\text { To what extent can the Mindful Moms to Be program be } \\ \text { carried out with participants using existing resources? }\end{array} & \begin{array}{l}\text { Survey, } \\ \text { Interview }\end{array} & \text { T2 } \\ \text { Demand } & \begin{array}{l}\text { To what extent is there a demand for the Mindful Moms } \\ \text { to Be program? }\end{array} & \begin{array}{l}\text { Survey, } \\ \text { Interview }\end{array} & \text { T2 } \\ \text { Sustainability } & \begin{array}{l}\text { To what extent can the Mindful Moms to Be program be } \\ \text { sustained by participants? }\end{array} & \begin{array}{l}\text { Survey, } \\ \text { Interview }\end{array} & \text { T2 } \\ & \end{array}$

\subsubsection{Outcome Data}

A 34-item survey included validated measures of mental health and wellbeing outcomes to assess the preliminary efficacy of the Mindful Moms-to-Be program at T1 and T2. The following validated instruments were included: the Edinburgh Postnatal Depression Scale (EPDS) [57], the General Anxiety Disorder-7 (GAD-7) [58], the Cohen Perceived Stress Scale (PSS) [59], the Brief Resilience Scale (BRS), and the Mindfulness Attention Awareness-5 (MAAS-5) [60]. Demographic information was collected including marital status (married, single and never married, divorced or separated), ethnicity (Hispanic or Non-Hispanic), race (Caucasian, African American, Asian or Pacific Islander, or Other), employment status (employed full time, employed part time, working without pay, unemployed, or student), total yearly household income (less than $\$ 25,000, \$ 25,000-\$ 49,999$, $\$ 50,000-\$ 74,999, \$ 75,000-\$ 99,999, \$ 100,000$ or greater), number of children (no children, 1 child, 2 children, 3 or more children), age (continuous), and gestational age (continuous).

\subsection{Data Analysis}

\subsubsection{Feasibility Data}

Feasibility constructs were explored by triangulating the quantitative and qualitative data. Frequencies and descriptive statistics were examined for all feasibility variables. Qualitative data analysis was conducted by a Research Assistant and followed best practice methods, including a deductive, theory-driven approach, and an inductive, data-driven approach [61,62]. The codebook contained a priori codes that align with the four general areas of feasibility mentioned above. Inductive coding was also used to allow for discovery of unique themes related to the feasibility of participation in remote MBIs specifically during COVID-19. The Research Assistant reviewed the data with the study team iteratively. If dis-concordance on the meaning of the codes and themes were present, a discussion occurred between team members to reach consensus on the coding structure. NVIVO software [63] was used for all qualitative analyses.

\subsubsection{Outcome Data}

To explore preliminary changes in mental health and wellbeing outcomes after participating in the Mindful Moms-to-Be program, frequency and descriptive statistics were explored related to each of the outcomes specified above. Independent samples t-tests were used to compare outcomes at T1 and T2 across individuals. Alpha $(\alpha)$ was set at 0.01. A more conservative correction (e.g. Bonferroni) was not utilized to account for multiple comparisons because of the exploratory nature of this pilot study [64]. IBM SPSS Statistics for Windows, Version 26.0 (SPSS) [65] software was used for statistical analysis. 


\section{Results}

Demographic characteristics of the full sample collected at baseline (T1) are displayed in Table 2. The average age of participants was 31 years and the average gestational age was 22 weeks. Most of the sample (82\%) were married; $15 \%$ of the sample were single and had never married and $4 \%$ were divorced or separated. About $2 / 3$ of participants (67\%) were primiparous, $26 \%$ had one child, and $7 \%$ had two children. Most (85\%) participants identified as non-Hispanic white, $7 \%$ as African American, $7 \%$ as Asian/Pacific Islander, and $4 \%$ as Hispanic. Most participants (82\%) were employed full-time. Household income varied; however, most participants (82\%) reported a yearly household income of $\$ 75,000$ or more. Finally, the sample was highly educated; $11 \%$ of participants had attended some college, $37 \%$ had a degree, and $52 \%$ had an advanced degree.

Table 2 Sample demographics of Mindful Moms-to-Be participants $(n=27)$.

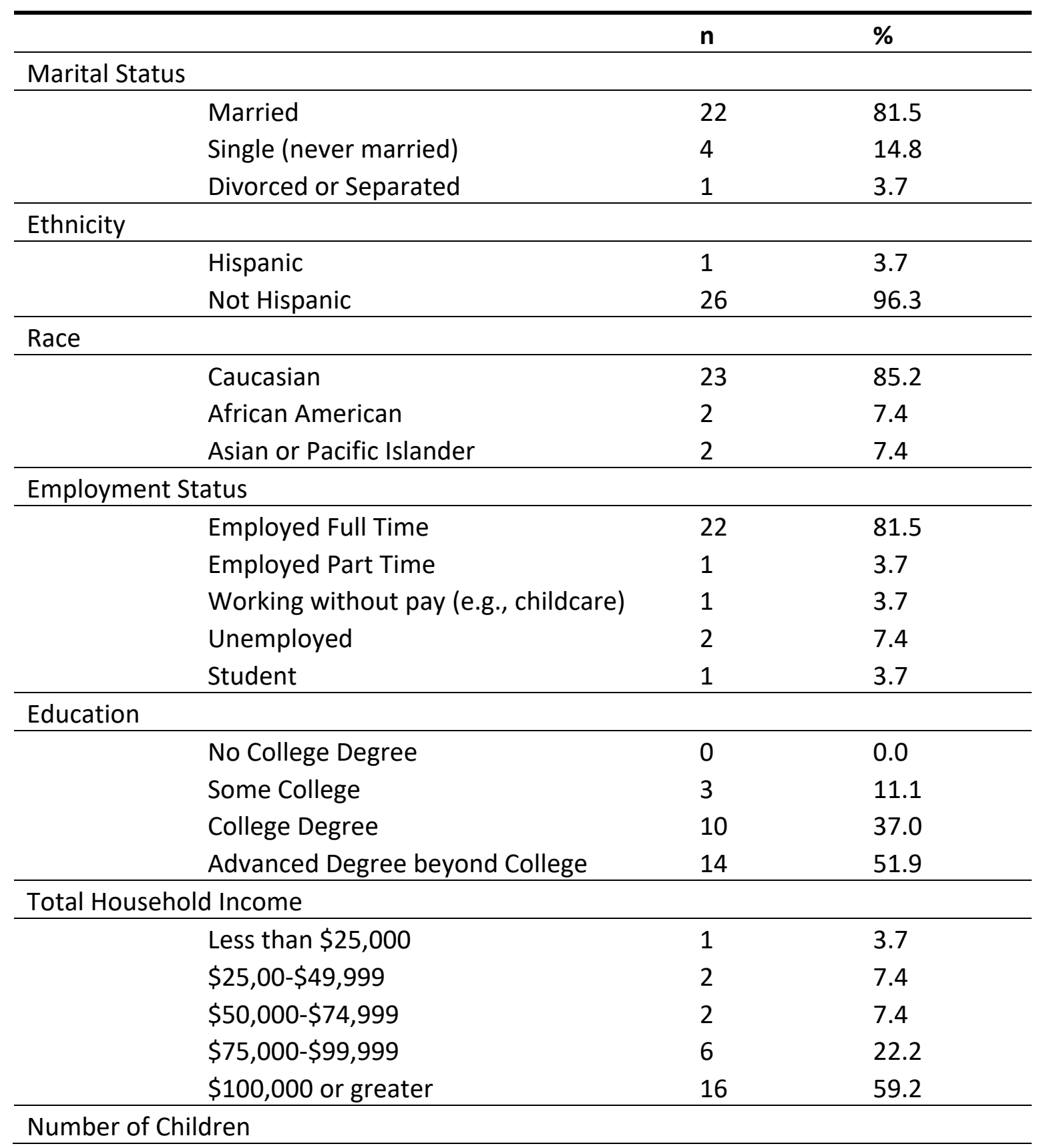




\begin{tabular}{llll}
\hline No Children & 18 & 66.7 \\
1 Child & 7 & 25.9 \\
2 Children & 2 & 7.4 \\
\hline & $\mathbf{M}$ & SD \\
\hline Age & 31.8 & 3.1 \\
Gestational Age & 22.2 & 6.3 \\
\hline
\end{tabular}

Eleven participants participated in the feasibility aim of this study (brief survey and interview) (41\% of sample) and results are displayed in Table 3. All participants reported being satisfied (18\%) or very satisfied (82\%) with the remotely delivered Mindful Moms-to-Be program. Additionally, when asked about perceptions surrounding the acceptability of remote participation versus inperson participation, $27 \%$ said they did not think format would impact their satisfaction with the program and almost half the sample (45\%) reported that remote participation was more satisfying than if they had participated in person. Approximately $1 / 3$ of the sample reported preferring inperson delivery, $46 \%$ preferred remote delivery, and $18 \%$ reported no preference. As one participant stated, "it's just the world we live in now." Participants reported that the synchronous meeting sessions and daily meditation practices were most helpful, whereas the homework assignments between sessions were least helpful.

Acceptability of remote programming may be related to an increased practicality associated with remote delivery. In this sample, $36 \%$ of participants reported that remote participation did not impact their ability to participate, $46 \%$ reported that it increased their ability to participate, and $18 \%$ reported that remote facilitation significantly increased their ability to participate. Additionally, $91 \%$ of the sample reported that their support system had a positive impact on their ability to practice mindfulness and participate in the Mindful Moms-to-Be program. One participant stated: "I think the virtual format was really comfortable to just be able to do from my own home." Demand was based on attendance at the weekly sessions and frequency of mindfulness practice engagement. Over $50 \%$ of participants attended all six sessions, $6 \%$ attended 5 sessions, $25 \%$ attended 4 sessions, and $18 \%$ attended half or less. However, some participants felt that additional sessions would have been beneficial. One participant said, "My main suggestion would be to expand on either the sessions or frequency of sessions to reinforce the practices and engage into topics a little more" and another said, "I would have I would have liked to do more, like an eight week or more session." Additionally, $73 \%$ of the sample reported engaging in mindfulness activities at least 5 days a week or more while participating in the Mindful Moms-to-be program.

Participants were asked how likely they were to sustain behaviors learned in the Mindful Momsto-Be program during the postpartum period. A majority (63\%) of participants reported feeling moderately or extremely likely to sustain the habits learned in the program after birth. Participants reported that the following resources would help them to sustain behaviors in the postpartum period: additional program sessions (82\%), check-ins with facilitators (73\%), online workshops or information sessions (73\%), trainings on topics related to mindfulness (64\%), and electronic information materials (45\%). One participant said, "I appreciated learning about different strategies that could be completed in two to three minutes, and I still use those nightly." 
Table 3 Mixed methods feasibility data of mindful Moms to Be.

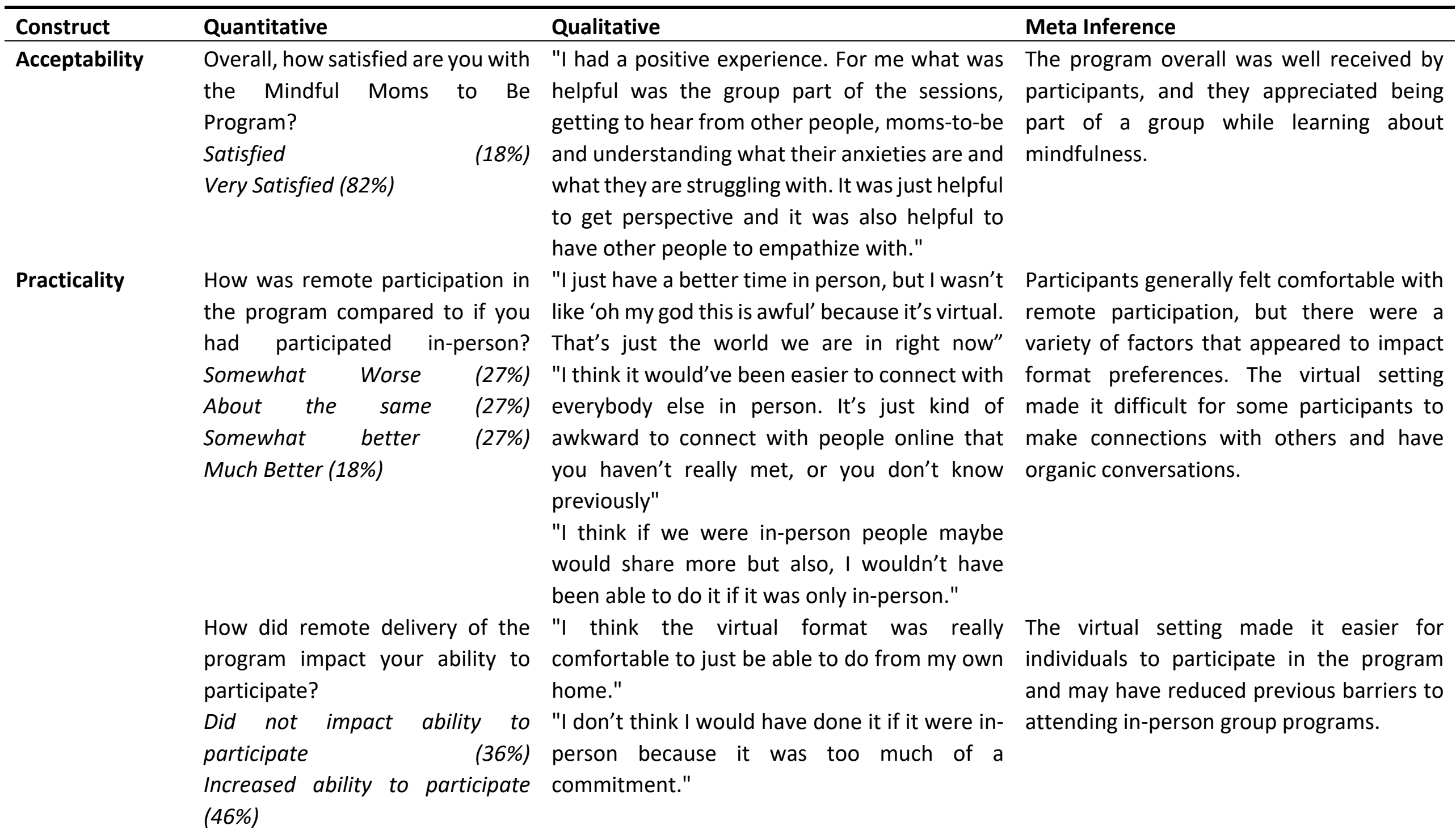


Significantly increased ability to participate (18\%)

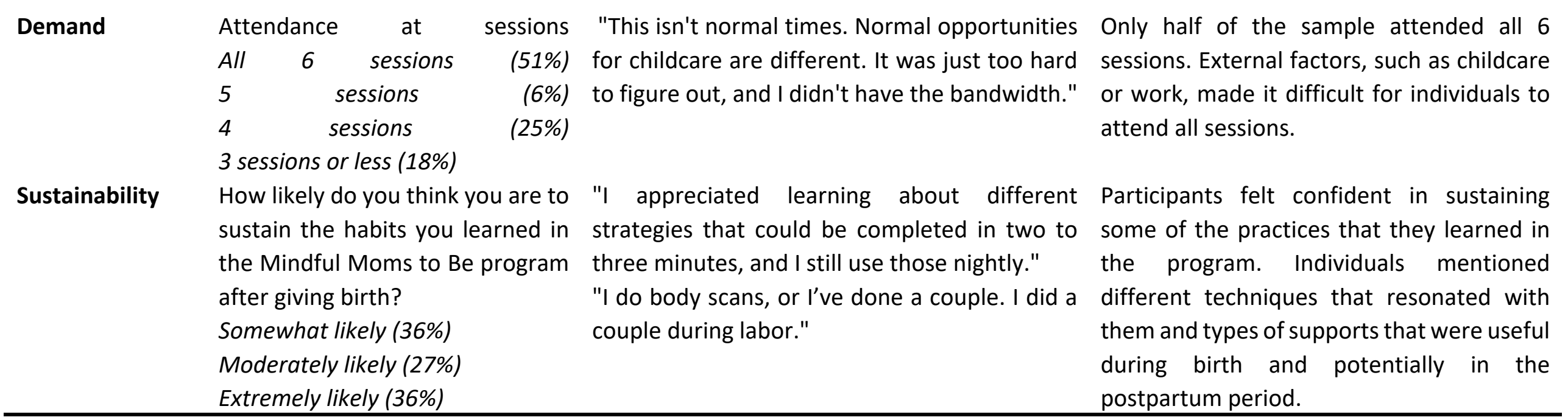


Outcome data related to the pre-post survey are displayed in Table 4 and Figure 1. After participation in the Mindful Moms-to-Be program, mindfulness scores increased $(t(26)=-1.07, p$ $=.30$ ) and loneliness scores decreased $(\mathrm{t}(26)=1.57, \mathrm{p}=.15)$ though these changes were not statistically significant. Participants reported statistically significant increases in resilience (t $(26=-$ $3.89, p<.01$ ) and statistically significant decreases in stress (t $(26)=3.45, p<.01$ ), depression (t (26) $=4.04)$, and anxiety $(\mathrm{t}(26)=4.23, \mathrm{p}<.01)$.

Table 4 Pre-Post changes in mental health- and wellbeing-related outcomes after participating in the prenatal Mindful Moms-to-Be program $(n=27)$.

\begin{tabular}{llllllll}
\hline Variables & Pre m(SD) & $\begin{array}{l}\text { Post } \\
\text { M(SD) }\end{array}$ & $\mathbf{t}$ & $\mathbf{p}$ & Cohen's d & $\begin{array}{l}\text { 95\% Cl for } \\
\text { Cohen's d }\end{array}$ \\
\hline Mindfulness & $20.0(4.2)$ & $20.7(4.6)$ & -1.07 & .30 & -.22 & -.62 & .19 \\
Resiliency & $3.2(.7)$ & $3.6(.8)$ & -3.89 & .00 & -.78 & -1.22 & -.32 \\
Loneliness & $5.1(1.9)$ & $4.6(1.4)$ & 1.47 & .15 & .29 & -.11 & .69 \\
Stress & $16.3(5.4)$ & $13.0(4.9)$ & 3.45 & .00 & .69 & .25 & 1.12 \\
Depression & $10.4(4.8)$ & $6.8(3.4)$ & 4.04 & .00 & .81 & .35 & 1.26 \\
Anxiety & $7.8(4.9)$ & $4.5(2.9)$ & 4.23 & .00 & .86 & .39 & 1.33 \\
\hline
\end{tabular}

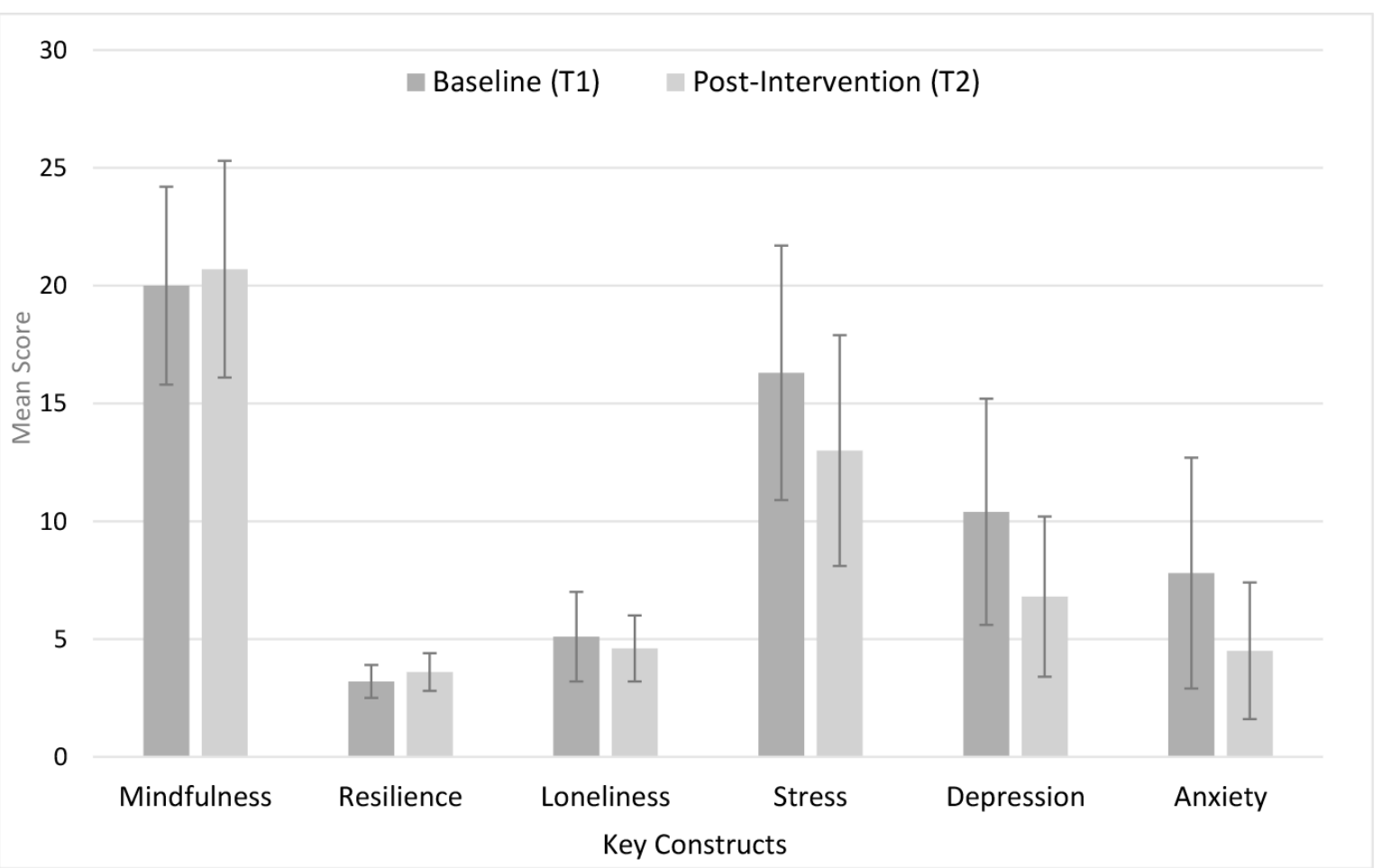

Figure 1 Mean change in key constructs after participation in the Mindful Moms-to-Be $\operatorname{program}(n=27)$.

\section{Discussion}

The purpose of this study was to present data on the feasibility and preliminary outcomes of a remotely delivered pilot project that utilized $\mathrm{MBCT}$ and $\mathrm{MBCP}$ to promote perinatal mental health 
and wellbeing during COVID-19. The mixed methods findings suggest that remote participation in the Mindful Moms-to-Be program is feasible and may lead to significant improvements in resilience, stress, depression, and anxiety. All participants reported being satisfied with remote delivery of the program and the majority reported that remote participation was either equally acceptable or more acceptable than in-person participation. Additionally, individuals felt that the synchronous meeting sessions were the most helpful component of the program. This is congruent with past findings related to remote delivery of other prenatal offerings such as breastfeeding education programs [66]. One study found that virtual delivery of childbirth education classes increased the demand for these types of prenatal courses (even outside of COVID restrictions) [67]. This is also echoed by a recent study that identified the increased utilization of essential prenatal care by telehealth delivery methods [68]. Collectively, these data suggest that remote delivery may increase accessibility and demand for MBIs during pregnancy.

Acceptability and practicality of remote participation may be closely correlated.

Most participants felt that remote participation increased their ability to participate. Participating remotely in prenatal programs may remove barriers such as transportation challenges, childcare, and time constraints [69]. Additionally, these data suggest that the presence of positive social supports that promote participation in mindfulness-related practices may increase the practicality of participation in prenatal wellbeing programs like Mindful Moms-to-Be. Similar studies have identified the importance of partner, friend, and family supports in promoting engagement and participation in prenatal wellbeing programs [70].

Demand for the program was high and about half of the sample reported preferring remote delivery; $1 / 5$ reported no preference. Though reported participation in daily mindfulness activities throughout the course of the program was high, attendance rates were variable. Little research has investigated the likelihood of sustaining prenatal wellbeing behaviors, specifically related to mindfulness-based practices, after birth. Data from this study suggest that participants during the prenatal period feel confident in their ability to sustain mindfulness behaviors in the postpartum period. Additionally, programmatic sessions, follow-up meetings with facilitators, trainings and additional electronic resources in the postpartum period specifically related to short, bite size practices, may be the most beneficial with respect to mitigating depression and anxiety [54]. One study similarly found that less time-consuming exercises were practiced more frequently postpartum [71]. Data on the sustainability of these behaviors 3-months postpartum, including postpartum mental health outcomes, will be analyzed and presented in a subsequent manuscript.

Preliminary outcome data suggests that the remotely delivered Mindful Moms-to-Be program may have significant impacts on numerous mental health and wellbeing outcomes, including resilience, depression, stress, and anxiety during the prenatal period among high SES, non-hispanic white women. These findings are aligned with previously implemented MBIs' impact on mental health outcomes in both the perinatal and non-pregnant, adult population [47, 72]. Contrary to our hypothesis, the program did not appear to increase measures of mindfulness. Future research is needed with a larger and more diverse sample size to investigate mediating factors that may impact improvements in mental health and wellbeing outcomes during pregnancy. Additionally, qualitative data will help to extrapolate specifically how perinatal MBl's are bolstering maternal mental health.

Strengths of this study include: 1) the focus on multiple mental health outcomes, including anxiety, instead of a sole focus on perinatal depression, 2) feasibility data related to remote participation in MBls among a prenatal sample, and 3) the use of mixed methods. Limitations 
include a small sample size, a convenience sample, and lack of heterogeneity with respect to socioeconomic status, race, and ethnicity. These factors may limit the generalizability of these data, though our findings align with past studies suggesting that implications may translate to other highresourced pregnant women.

These findings imply that remotely delivered MBIs during pregnancy may be acceptable and practical for pregnant individuals, increase demand, and potentially lead to sustainable changes in the postpartum period. Remote participation may eliminate barriers related to time constraints, childcare, discomfort, and transportation-related challenges and bolster engagement. Mindful Moms-to-Be may be particularly protective for pregnant individuals during COVID-19 specifically because of the significant impact on mental health outcomes, including anxiety. However, additional quantitative and qualitative data is needed to better explore how these findings may or may not translate to more diverse populations and specific barriers related to the feasibility of participation in remotely-delivered MBIs among low-SES and minority women. These data highlight the need for future research to explore the impacts of the remote Mindful Moms-to-Be program with more heterogenous samples and sustained postpartum impacts among perinatal populations.

\section{Acknowledgments}

We thank all co-authors for their contribution to this study in additional to all pregnant individuals who participated in the Mindful Moms-to-Be Program.

\section{Author Contributions}

CF is the lead of this study and was responsible for all project management and data collection and analysis. JW collected and analyzed qualitative data. JP developed the feasibility evaluation plan and developed the corresponding tools. JW and MS facilitated the Mindful Moms-to-Be program and supported interpretation of the findings. JL was the primary mentor for this project and provided support and guidance throughout implementation. All co-authors contributed to the writing and editing of this manuscript.

\section{Funding}

This study was funded by the Ludeman Family Center for Women's Health Research at the University of Colorado Anschutz Medical Campus.

\section{Competing Interests}

The authors have declared that no competing interests exist.

\section{References}

1. Gluckman PD, Hanson MA, Buklijas T. A conceptual framework for the developmental origins of health and disease. J Dev Orig Health Dis. 2010; 1: 6-18.

2. Sandman CA, Davis EP, Buss C, Glynn LM. Exposure to prenatal psychobiological stress exerts programming influences on the mother and her fetus. Neuroendocrinology. 2012; 95: 8-21.

3. Gluckman PD, Hanson MA, Mitchell MD. Developmental origins of health and disease: Reducing 
the burden of chronic disease in the next generation. Genome Med. 2010; 2: 14.

4. Shonkoff JP. Building a new biodevelopmental framework to guide the future of early childhood policy. Child Dev. 2010; 81: 357-367.

5. Harville EW, Savitz DA, Dole N, Herring AH, Thorp JM. Stress questionnaires and stress biomarkers during pregnancy. J Womens Health. 2009; 18: 1425-1433.

6. Ehsanpour S, Shabangiz A, Bahadoran P, Kheirabadi GR. The association of depression and preterm labor. Iran J Nurs Midwifery Res. 2012; 17: 275-278.

7. Bussieres EL, Tarabulsy GM, Pearson J, Tessier R, Forest JC, Giguere Y. Maternal prenatal stress and infant birth weight and gestational age: A meta-analysis of prospective studies. Dev Rev. 2015; 36: 179-199.

8. Nicholson L, Lecour S, Sliwa K, Wedegartner S, Kindermann I, Bohm M. Assessing perinatal depression as an indicator of risk for pregnancy-associated cardiovascular disease: Review articles. Cardiovasc J Afr. 2016; 27: 119-122.

9. Talge NM, Neal C, Glover V, Early Stress, Translational Research and Prevention Science Network: Fetal and Neonatal Experience on Child and Adolescent Mental Health. Antenatal maternal stress and long-term effects on child neurodevelopment: How and why? J Child Psychol Psychiatry. 2007; 48: 245-261.

10. Dunkel Schetter C. Psychological science on pregnancy: Stress processes, biopsychosocial models, and emerging research issues. Annu Rev Psychol. 2011; 62: 531-558.

11. Melville JL, Gavin A, Guo Y, Fan MY, Katon WJ. Depressive disorders during pregnancy: Prevalence and risk factors in a large urban sample. Obstet Gynecol. 2010; 116: 1064.

12. Li J, Olsen J, Vestergaard M, Obel C, Kristensen JK, Virk J. Prenatal exposure to bereavement and Type-2 diabetes: A Danish longitudinal population based study. PLoS ONE. 2012; 8: e43508.

13. Okagbue HI, Adamu PI, Bishop SA, Oguntunde PE, Opanuga AA, Akhmetshin EM. Systematic review of prevalence of antepartum depression during the trimesters of pregnancy. Open Access Maced J Medical Sci. 2019; 7: 1555-1560.

14. Fawcett EJ, Fairbrother N, Cox ML, White IR, Fawcett JM. The prevalence of anxiety disorders during pregnancy and the postpartum period: A multivariate Bayesian meta-analysis. J Clin Psychiatry. 2019; 80: 0-0.

15. Chow A, Dharma C, Chen E, Mandhane PJ, Turvey SE, Elliott SJ, et al. Trajectories of depressive symptoms and perceived stress from pregnancy to the postnatal period among Canadian women: Impact of employment and immigration. Am J Public Health. 2019; 109: S197-S204.

16. Kingston D, Sword W, Krueger P, Hanna S, Markle-Reid M. Life course pathways to prenatal maternal stress. J Obstet Gynecol Neonatal Nurs. 2012; 41: 609-626.

17. Kuzawa CW, Quinn EA. Developmental origins of adult function and health: Evolutionary hypotheses. Annu Rev Anthropol. 2009; 38: 131-147.

18. Farewell CV, Thayer ZM, Tracer DP, Morton S. Prenatal stress exposure and early childhood BMI: Exploring associations in a New Zealand context. Am J Hum Biol. 2018; 30: e23116.

19. Liu GT, Dancause KN, Elgbeili G, Laplante DP, King S. Disaster-related prenatal maternal stress explains increasing amounts of variance in body composition through childhood and adolescence: Project ice storm. Environ Res. 2016; 150: 1-7.

20. Farewell CV, Thayer ZM, Puma JE, Morton S. Exploring the timing and duration of maternal stress exposure: Impacts on early childhood BMI. Early Hum Dev. 2018; 117: 15-19.

21. Farewell CV, Jewell J, Walls J, Leiferman JA. A mixed-methods pilot study of perinatal risk and 
resilience during COVID-19. J Prim Care Community Health. 2020; 11: 2150132720944074.

22. Cameron EE, Joyce KM, Delaquis CP, Reynolds K, Protudjer JL, Roos LE. Maternal psychological distress \& mental health service use during the COVID-19 pandemic. J Affect Disord. 2020; 276: 765-774.

23. Tomfohr-Madsen LM, Racine N, Giesbrecht GF, Lebel C, Madigan S. Depression and anxiety in pregnancy during COVID-19: A rapid review and meta-analysis. Psychiatry Res. 2021; 300: 113912.

24. Grigoriadis S, Graves L, Peer M, Mamisashvili L, Tomlinson G, Vigod SN, et al. Maternal anxiety during pregnancy and the association with adverse perinatal outcomes: Systematic review and meta-analysis. J Clin Psychiatry. 2018; 79: 0-0.

25. Dubber S, Reck C, Müller M, Gawlik S. Postpartum bonding: The role of perinatal depression, anxiety and maternal-fetal bonding during pregnancy. Arch Womens Ment Health. 2015; 18: 187-195.

26. Netsi E, Pearson RM, Murray L, Cooper P, Craske MG, Stein A. Association of persistent and severe postnatal depression with child outcomes. JAMA Psychiatry. 2018; 75: 247-253.

27. Howard LM, Khalifeh H. Perinatal mental health: A review of progress and challenges. World Psychiatry. 2020; 19: 313-327.

28. Hutchens BF, Kearney J. Risk factors for postpartum depression: An umbrella review. J Midwifery Womens Health. 2020; 65: 96-108.

29. Dashraath P, Wong JL, Lim MX, Lim LM, Li S, Biswas A, et al. Coronavirus disease 2019 (COVID19) pandemic and pregnancy. Am J Obstet Gynecol. 2020; 222: 521-531.

30. Ahmed QA, Memish ZA. The cancellation of mass gatherings (MGs)? Decision making in the time of COVID-19. Travel Med Infect Dis. 2020; 34: 101631.

31. Wosik J, Fudim M, Cameron B, Gellad ZF, Cho A, Phinney D, et al. Telehealth transformation: COVID-19 and the rise of virtual care. J Am Med Inform Assoc. 2020; 27: 957-962.

32. Hawes CG. The role of social isolation as a predetermining factor for postpartum depression development: A literature review. Chapel Hill, NC: University of North Carolina at Chapel Hill; 2020.

33. Biaggi A, Conroy S, Pawlby S, Pariante CM. Identifying the women at risk of antenatal anxiety and depression: A systematic review. J Affect Disord. 2016; 191: 62-77.

34. Norhayati MN, Hazlina NN, Asrenee AR, Emilin WW. Magnitude and risk factors for postpartum symptoms: A literature review. J Affect Disord. 2015; 175: 34-52.

35. Harrison V, Moulds ML, Jones K. Perceived social support and prenatal wellbeing; the mediating effects of loneliness and repetitive negative thinking on anxiety and depression during the COVID-19 pandemic. Women Birth. 2021. Doi: 10.1016/j.wombi.2020.12.014.

36. Javaid S, Barringer S, Compton SD, Kaselitz E, Muzik M, Moyer CA. The impact of COVID-19 on prenatal care in the United States: Qualitative analysis from a survey of 2519 pregnant women. Midwifery. 2021; 98: 102991.

37. Astin JA, Shapiro SL, Eisenberg DM, Forys KL. Mind-body medicine: State of the science, implications for practice. J Am Board Fam Med. 2003; 16: 131-147.

38. Kabat-Zinn J. An outpatient program in behavioral medicine for chronic pain patients based on the practice of mindfulness meditation: Theoretical considerations and preliminary results. Gen Hosp Psychiatry. 1982; 4: 33-47.

39. Vieten C, Astin J. Effects of a mindfulness-based intervention during pregnancy on prenatal 
stress and mood: Results of a pilot study. Arch Womens Ment Health. 2008; 11: 67-74.

40. Kuyken W, Byford S, Taylor RS, Watkins E, Holden E, White K, et al. Mindfulness-based cognitive therapy to prevent relapse in recurrent depression. J Consult Clin Psychol. 2008; 76: 966-978.

41. Kuyken W, Watkins E, Holden E, White K, Taylor RS, Byford S, et al. How does mindfulness-based cognitive therapy work? Behav Res Ther. 2010; 48: 1105-1112.

42. Ma SH, Teasdale JD. Mindfulness-based cognitive therapy for depression: Replication and exploration of differential relapse prevention effects. J Consult Clin Psychol. 2004; 72: 31-40.

43. Matvienko-Sikar K, Lee L, Murphy G, Murphy L. The effects of mindfulness interventions on prenatal well-being: A systematic review. Psychol Health. 2016; 31: 1415-1434.

44. Shapiro SL, Oman D, Thoresen CE, Plante TG, Flinders T. Cultivating mindfulness: Effects on wellbeing. J Clin Psychol. 2008; 64: 840-862.

45. Keng SL, Smoski MJ, Robins CJ. Effects of mindfulness on psychological health: A review of empirical studies. Clin Psychol Rev. 2011; 31: 1041-1056.

46. Felder JN, Roubinov D, Bush NR, Coleman-Phox K, Vieten C, Laraia B, et al. Effect of prenatal mindfulness training on depressive symptom severity through 18-months postpartum: $A$ latent profile analysis. J Clin Psychol. 2018; 74: 1117-1125.

47. Lever Taylor B, Cavanagh K, Strauss C. The effectiveness of mindfulness-based interventions in the perinatal period: A systematic review and meta-analysis. PloS ONE. 2016; 11: e0155720.

48. Osborne LM, Kimmel MC, Surkan PJ. The crisis of perinatal mental health in the age of COVID19. Matern Child Health J. 2021; 25: 349-352.

49. Motrico E, Bina R, Domínguez-Salas S, Mateus V, Contreras-García Y, Carrasco-Portiño M, et al. Impact of the COVID-19 pandemic on perinatal mental health (Riseup-PPD-COVID-19): Protocol for an international prospective cohort study. BMC Public Health. 2021; 21: 368.

50. Zhang $\mathrm{H}$, Emory EK. A mindfulness-based intervention for pregnant African-American women. Mindfulness. 2015; 6: 663-674.

51. Lazarus RS, Folkman S. Transactional theory and research on emotions and coping. Eur J Pers. 1987; 1: 141-169.

52. Duncan LG, Bardacke N. Mindfulness-based childbirth and parenting education: Promoting family mindfulness during the perinatal period. J Child Fam Stud. 2010; 19: 190-202.

53. Dimidjian S, Goodman SH, Felder JN, Gallop R, Brown AP, Beck A. An open trial of mindfulnessbased cognitive therapy for the prevention of perinatal depressive relapse/recurrence. Arch Womens Ment Health. 2015; 18: 85-94.

54. Dimidjian S, Goodman SH, Felder JN, Gallop R, Brown AP, Beck A. Staying well during pregnancy and the postpartum: A pilot randomized trial of mindfulness-based cognitive therapy for the prevention of depressive relapse/recurrence. J Consult Clin Psychol. 2016; 84: 134-145.

55. Harris PA, Taylor R, Thielke R, Payne J, Gonzalez N, Conde JG. Research electronic data capture (REDCap)-a metadata-driven methodology and workflow process for providing translational research informatics support. J Biomed Inform. 2009; 42: 377-381.

56. Bowen DJ, Kreuter M, Spring B, Cofta-Woerpel L, Linnan L, Weiner D, et al. How we design feasibility studies. Am J Prev Med. 2009; 36: 452-457.

57. Cox JL, Holden JM, Sagovsky R. Detection of postnatal depression: Development of the 10-item Edinburgh postnatal depression scale. Br J Psychiatry. 1987; 150: 782-786.

58. Spitzer RL, Kroenke K, Williams JB, Löwe B. A brief measure for assessing generalized anxiety disorder: The GAD-7. Arch Intern Med. 2006; 166: 1092-1097. 
59. Cohen S, Kamarck T, Mermelstein R. Perceived stress scale. Measuring stress: A guide for health and social scientists. 1994; 10: 1-2.

60. Mackillop J, Anderson EJ. Further psychometric validation of the mindful attention awareness scale (MAAS). J Psychopathol Behav Assess. 2007; 29: 289-293.

61. Maxwell J, Bickman L, Rog DJ. The SAGE handbook of applied social research methods. Thousand Oaks: SAGE Publications Inc.; 2009.

62. Green J, Thorogood N. Qualitative methods for health research. Introducing qualitative methods. 4th ed. Los Angeles: SAGE; 2018.

63. Guizzo BS, de Oliveira DL. The software QSR Nvivo 2.0 in qualitative data analysis: A tool for health and human sciences researches. Rev Gaucha Enferm. 2003; 24: 53-60.

64. Vasilopoulos T, Morey TE, Dhatariya K, Rice MJ. Limitations of significance testing in clinical research: A review of multiple comparison corrections and effect size calculations with correlated measures. Anesth Analg. 2016; 122: 825-830.

65. Verma JP. Data analysis in management with SPSS software. New Delhi: Springer Science \& Business Media; 2012.

66. Palmquist AE, Parry KC, Wouk K, Lawless GC, Smith JL, Smetana AR, et al. Ready, set, baby live virtual prenatal breastfeeding education for COVID-19. J Hum Lact. 2020; 36: 614-618.

67. Pasadino F, DeMarco K, Lampert E. Connecting with families through virtual perinatal education during the COVID-19 pandemic. MCN Am J Matern Child Nurs. 2020; 45: 364-370.

68. Goetz M, Schiele C, Müller M, Matthies LM, Deutsch TM, Spano C, et al. Effects of a brief electronic mindfulness-based intervention on relieving prenatal depression and anxiety in hospitalized high-risk pregnant women: Exploratory pilot study. J Medical Internet Res. 2020; 22: e17593.

69. Fryer K, Delgado A, Foti T, Reid CN, Marshall J. Implementation of obstetric telehealth during COVID-19 and beyond. Matern Child Health J. 2020; 24: 1104-1110.

70. Walsh TB, Carpenter E, Costanzo MA, Howard L, Reynders R. Present as a partner and a parent: Mothers' and fathers' perspectives on father participation in prenatal care. Infant Ment Health J. 2021; 42: 386-399.

71. Cunningham SD, Grilo S, Lewis JB, Novick G, Rising SS, Tobin JN, et al. Group prenatal care attendance: Determinants and relationship with care satisfaction. Matern Child Health J. 2017; 21: 770-776.

72. Carmody J, Baer RA. Relationships between mindfulness practice and levels of mindfulness, medical and psychological symptoms and well-being in a mindfulness-based stress reduction program. J Behav Med. 2008; 31: 23-33. 
OBM Integrative and Complementary Medicine 2021; 6(3), doi:10.21926/obm.icm.2103028

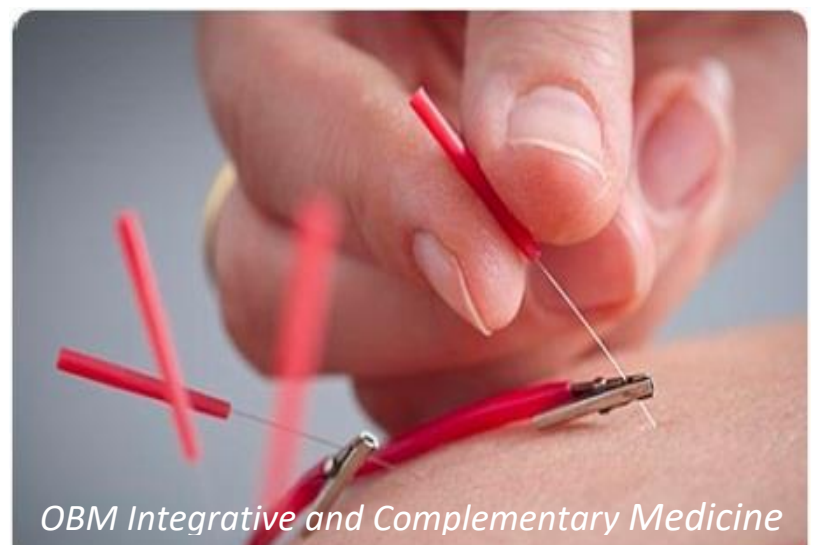

Enjoy $O B M$ Integrative and Complementary Medicine by:

1. Submitting a manuscript

2. Joining in volunteer reviewer bank

3. Joining Editorial Board

4. Guest editing a special issue

For more details, please visit:

http://www.lidsen.com/journals/icm 